\title{
Descriptive study of interprofessional collaboration between physicians and osteopaths for the pediatric population in Quebec, Canada
}

\author{
Chantal Morin ${ }^{1 *}$, Johanne Desrosiers ${ }^{2}$ and Isabelle Gaboury ${ }^{1}$
}

\begin{abstract}
Background: Osteopathy is an increasingly popular healthcare approach that uses a wide variety of therapeutic manual techniques to address pain and somatic dysfunction. In Quebec, Canada, osteopathy is the complementary medicine most often recommended by family physicians. However, factors fostering the development of interprofessional collaboration (IPC) between physicians and osteopaths are unknown. This study aimed to describe the current situation in terms of IPC among practitioners working with pediatric patients.

Methods: A self-administered questionnaire was sent to osteopaths, family physicians, and pediatricians involved with pediatric patients in the province of Quebec. The postal questionnaire captured general knowledge about osteopathy and its practice parameters and role, sources of information, communication aspects including having a professional relationship and referrals, and influence of the upcoming government regulation. Quantitative data from the questionnaires were analyzed using descriptive statistics. Logistic regression model for factors associated with osteopathic referrals and multiple linear regression analyses for the number of correct answers about general osteopathic practice parameters were performed.
\end{abstract}

Results: A total of 274 physicians (155 family physicians (response rate 13\%) and 119 pediatricians (17\%)) and 297 osteopaths (42\%) completed the survey. According to physicians, osteopathy was most appropriate for musculoskeletal pain $(241 ; 91 \%)$ and plagiocephaly $(235 ; 88 \%)$. Osteopathic referral was positively associated with having a professional relationship (odds ratio [OR] 4.10 (95\% confidence interval $[\mathrm{Cl}] 2.12 ; 7.95), p<0.001$ ), personal consultation (OR $2.58(95 \% \mathrm{Cl} 1.35 ; 4.93), p=0.004)$, community-based practice (OR $1.89(95 \% \mathrm{Cl} 1.03 ; 3.47)$, $p=0.040)$, and belief in the active role of osteopathy for pediatric conditions ( $\mathrm{OR} 1.22(95 \% \mathrm{Cl} 1.01 ; 1.47), p=0.042)$. The majority of physicians (72\%) and osteopaths (62\%) considered the upcoming government regulation of osteopathy a positive factor for collaboration.

Conclusion: Some collaboration already exists among these practitioners, including mutual referrals, but optimizing this collaboration still poses some challenges.

Keywords: Collaboration, Complementary medicine, Family medicine, Osteopathy, Pediatrics, Primary care, Referral, Survey

\footnotetext{
* Correspondence: chantal.morin@usherbrooke.ca

1Department of Family Medicine and Emergency Medicine and School of

Rehabilitation, Faculty of Medicine and Health Sciences, Université de

Sherbrooke, Sherbrooke, Quebec, Canada

Full list of author information is available at the end of the article
} 


\section{Background}

Osteopathy is a complementary and alternative medicine (CAM) that is growing in popularity in many countries including in Canada and especially in the province of Quebec [1, 2] where it is the CAM most often recommended by family physicians [3]. Osteopaths use a wide variety of therapeutic manual techniques to address pain and somatic dysfunction in order to restore the person's natural state of physical well-being. Osteopathic manipulative treatments can facilitate the body's normal selfregulation and self-healing mechanisms by addressing areas of tissue strain, stress, restriction, or dysfunction that may impede normal function [4]. In Quebec, osteopathic consultations for the pediatric population are frequent [5].The most common reasons include cranial deformities, torticollis, postnatal preventive healthcare, otolaryngology concerns, gastroesophageal reflux, motor or cognitive development concerns, musculoskeletal, respiratory and digestive problems, headaches, and sleep disturbances [2]. Such functional disorders are known to pose a significant challenge to conventional medicine [6-8] and frequently require an interprofessional approach $[9,10]$.

Interprofessional collaboration (IPC) in primary care may be defined as a set of relationships and interactions that allows professionals to share their knowledge, expertise and experience to concomitantly address complex client needs [11]. Many interactional (interpersonal relationships including willingness to collaborate, trust, communication and mutual respect), organizational and systemic factors (social, cultural, professional and education systems) are known to influence IPC [12]. In the context of IPC between conventional medicine and CAM, differences in work culture, paradigms, knowledge and language are factors preventing interactions and limiting collaborations [13]. Systemic factors such as liability concerns [14] and power disparities between physicians and CAM practitioners $[13,15,16]$ also influence the collaboration process. There is no legislation yet controlling the training and the title, or regulating the practice of non-physician osteopaths in Quebec. In order to protect the public, the Office des professions du Québec (provincial regulatory body for all health care professions) is currently working towards a legislative framework to regulate the practice of osteopathy [17]. To date, no studies have been published about IPC between physicians and osteopaths for pediatric patients. The absence of studies about the factors enabling the development of IPC between physicians and osteopaths for pediatric and other patients, coupled with the increase in osteopathy consultations by parents, points to the need to study this working arrangement, especially given the pending governmental legislation of the osteopathic profession in Quebec.
This study aimed to describe the current general situation in the province of Quebec, Canada, in terms of IPC between physicians and non-physician osteopaths working with pediatric clients. More specifically, three descriptive aspects were examined: 1) physicians' knowledge about osteopathic practice parameters and role; 2) communication including referrals and professional relationships; and 3) influence of the pending government regulation of osteopathy. In addition, factors associated with osteopathic referrals by physicians and factors linked to physicians' knowledge of key osteopathic practice parameters were explored from descriptive data.

\section{Methods}

\section{Study design, participants and recruitment procedure}

This survey, conducted between September and November 2014, was the first (quantitative) phase of a larger sequential mixed method study aimed at improving understanding of IPC between physicians and non-physician osteopaths working with pediatric patients. Postal questionnaire were sent to all family physicians with a pediatric population and pediatricians without a subspecialty in Quebec, according to Scott's MD Select 2013 directory as well as all members of Ostéopathie Québec (largest professional association in the province). A total of 2802 questionnaires were initially mailed to family physicians $(N=1327)$, pediatricians $(N=738)$ and osteopaths $(N=737)$. Assuming a $20 \%$ response rate for physicians/pediatricians and $40 \%$ for osteopaths, it is estimated that errors would be limited to $5 \%$ and $6 \%$ respectively, 19 times out of 20 .

Efforts to maximize participation in the study included personalized mailing of questionnaires. The survey was also promoted on the Ostéopathie Québec website, and the first author attended various medical and osteopathic events in fall 2014. A reminder postcard was sent two weeks after the initial mailing and a second questionnaire two weeks later. Study aims were clearly described at the beginning of the questionnaire. Completing and returning the questionnaire anonymously indicate informed consent from participants. The study was approved by the Centre hospitalier universitaire de Sherbrooke ethics committee for health research on humans (\#14-115).

\section{Instrument (survey questionnaire)}

The physician and osteopath versions of the survey questionnaire were developed using a three-stage iterative process comprising developmental stage, question testing stage, and pilot stage [18].

The initial version of the questionnaire was based on a literature review of existing questionnaires regarding IPC between conventional medicine and CAM practitioners. It was divided into three categories according to the study's conceptual model, the Chiropractor-physician model of collaborative practice of Mior et al., (2010): 
practice parameters, communication, and care delivery parameters including regulation [14]. We considered existing questionnaires on physicians' [19] or other health professionals' [20] knowledge of osteopathy, continuing education and sources of information about osteopathy [20] or CAM for the pediatric population [21], experiences of collaboration with CAM practitioners [21], referrals [19, 20, 22], communication and professional relationships [20], and sociodemographic variables related to collaboration [19-22]. This first version was pretested with two physicians, one pediatrician, three osteopaths, and an expert on IPC and questionnaire development. The modified version was piloted (procedure and duration) in individual face-to-face cognitive interviews with two physicians, two pediatricians and four osteopaths. It took 8 to 10 minutes to complete the survey. The final version of the questionnaires covered: a) knowledge about osteopathic practice parameters including 10 questions regarding general aspects, 10 questions concerning belief in the active role of osteopathy for specific pediatric conditions, and one question regarding sources of information about osteopathy (physician version only); b) communication aspects including interpersonal relationships, referrals, and communication methods (7 questions); c) influence of regulation of osteopathy on IPC (1 question); and d) sociodemographic data: gender, years of experience, type of practice, discipline, personal consultation of an osteopath (physician version), and presence of a physician in the working environment (osteopath version). Qualitative comments could be added by participants at the end of the questionnaire.

\section{Data analysis}

The number of correct answers out of 10 was computed for the questions on the general aspects of practice parameters. Similarly, the total number of positive answers for the 10 questions on belief in the role of osteopathy for specific pediatric conditions was calculated. Means and standard deviations were generated. Other quantitative data from the questionnaires regarding communication, influence of regulation, and sociodemographic information were analyzed using descriptive statistics (frequencies and percentages).

Chi-squared or $t$ tests (depending on the type of dependent variable) were first used to identify statistically significant variables associated with osteopathic referrals by physicians (yes or no) and factors associated with more correct answers out of 10 about general osteopathic practice parameters. Independent variables that were significantly $(p<0.05)$ associated were introduced in a stepwise backward logistic regression model for factors associated with osteopathic referrals or in multiple linear regression analyses for the number of correct answers about general osteopathic practice parameters.
Normality of the knowledge variable was verified visually with a histogram and a residual analysis was conducted to verify basic assumptions for both regression models. All analyses were performed using SPSS 17 (Chicago, IL).

\section{Results}

After excluding undeliverable questionnaires, retired physicians and osteopaths and specialized family physicians (see Fig. 1), a total of 274 physicians (155 family physicians out of 1192 (response rate 13\%) and 119 pediatricians out of 708 (response rate 17\%)) and 297 osteopaths out of 714 (response rate 42\%) completed the survey. All surveys were considered for analysis. The respondents' characteristics are summarized in Table 1 . The majority were women, 122 physicians (45\%) had consulted an osteopath for themselves, and 38 osteopaths (13\%) had a physician working in the same clinic.

\section{Physicians' knowledge about osteopathic practice parameters}

Physicians correctly answered 7.2 (SD 1.8) questions out of 10 on average concerning general knowledge about the practice of osteopathy (Table 2). Level of osteopathic education and regulation status of the profession were the questions with the lowest percentage of correct answers. However, almost all physicians agreed that being a physical therapist is not a prerequisite for being an osteopath in Quebec and that osteopaths evaluate and mobilize all body tissues, not just vertebrae. There were 6.8 (SD 1.91) positive answers for belief in the role of osteopathy for specific pediatric conditions (Table 2). A high percentage of physicians think that osteopathy has a role in addressing musculoskeletal pain as well as torticollis and plagiocephaly. When asked what their sources of information about osteopathy are (multiple answers were allowed), more than half of the physicians mentioned asking information directly to an osteopath (52\%), followed by patients (51\%), and to other health professionals $(21 \%)$. Information was also obtained by personal searches (17\%), from scientific articles (10\%), and during continuing education sessions (8\%).

\section{Communication}

Table 3 outlines communication aspects for each type of practitioner. More than one third of respondents had a professional relationship with the other practitioner. Nearly half the physicians referred pediatric patients to osteopaths at least once a month. The large majority of respondents ( $81 \%$ of physicians and $85 \%$ of osteopaths) said that communication was required for common patients and that their preferred communication methods were letters or verbal communication through the patient. 


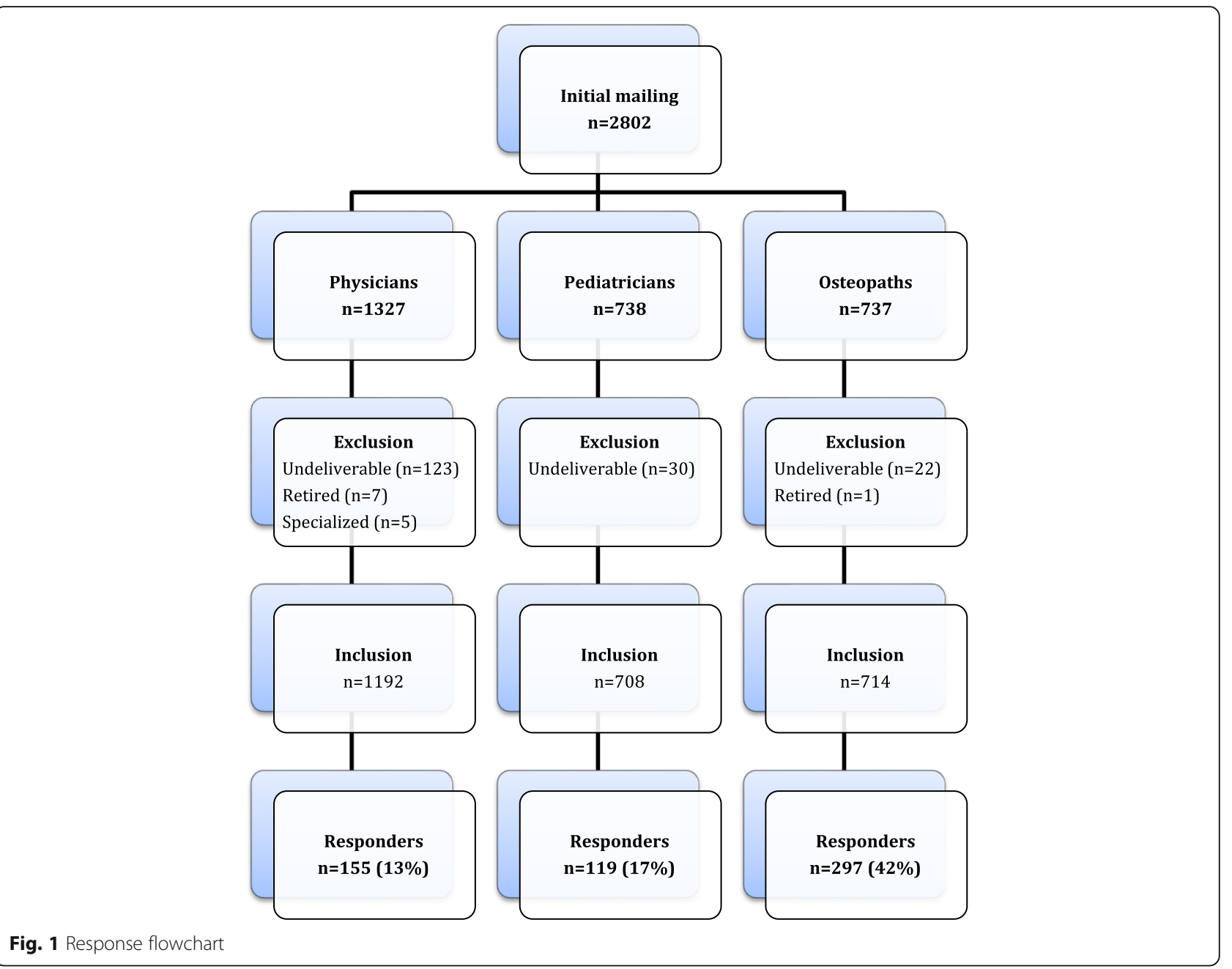

\section{Influence of regulation}

The majority of physicians (72\%) and osteopaths (62\%) said they would be moderately or greatly influenced by the upcoming government regulation of osteopathy and the creation of university-based osteopathic programs in Quebec. Eighteen percent of physicians and 22\% of osteopaths would not be very influenced and respectively $10 \%$ and $16 \%$ said they would not be influenced at all by regulation, either because they already collaborated or because they had no interest in physician-osteopath collaboration (comments on the survey).

\section{Factors associated with osteopathic referrals by physicians}

Variables statistically associated with osteopathic referrals by physicians at the bivariate level were: gender (female), profession (family physician), general knowledge about practice parameters, direct sources of information about osteopathy, belief in the active role of osteopathy for pediatric conditions, community practice, personal consultation of an osteopath, and having a professional relationship. These last four variables remained in the final stepwise backward logistic regression model (Table 4).

\section{Factors associated with knowledge about osteopathic general practice parameters}

In the final linear regression model $F(7247)=9.117$ $(p<0.001), 20.5 \%$ of the variance in the number of correct answers (knowledge) concerning general osteopathic practice parameters was explained by having a direct source of information about osteopathy (osteopath or other health professional; $p=0.009$ ) and the number of positive answers for belief in the appropriateness of osteopathy for pediatric conditions $(p<0.001)$ while considering all the other bivariate associated variables in the model (professional relationship, personal consultation with an osteopath, osteopathic referrals, importance of having an osteopath among collaborators (quite or very important versus not important), and gender). 
Table 1 Characteristics of participants

\begin{tabular}{|c|c|c|}
\hline \multirow[t]{2}{*}{ Characteristics } & Physicians $(n=274)$ & Osteopaths $(n=297)$ \\
\hline & Freq. $(\% ; 95 \% \mathrm{Cl})^{\mathrm{a}}$ & Freq. $(\% ; 95 \% \mathrm{Cl})$ \\
\hline Gender (female) & $202(73.7 ; 68.0,78.8)$ & $236(79.5 ; 74.3,83.8)$ \\
\hline \multicolumn{3}{|l|}{ Working experience (yrs): } \\
\hline $0-4$ & $22(8.1 ; 5.3,12.2)$ & $55(18.5 ; 14.4,23.5)$ \\
\hline $5-9$ & $34(12.5 ; 8.9,17.2)$ & $97(32.7 ; 27.4,38.4)$ \\
\hline $10-14$ & $34(12.5 ; 8.9,17.2)$ & $64(21.5 ; 17.1,26.8)$ \\
\hline $15-20$ & $45(16.5 ; 12.4,21.6)$ & $43(14.5 ; 10.8,19.1)$ \\
\hline+21 & $137(50.4 ; 44.3,56.5)$ & $38(12.8 ; 9.3,17.3)$ \\
\hline \multicolumn{3}{|l|}{ Type of practice ${ }^{b}$ : } \\
\hline Group & $75(27.7 ; 22.5,33.5)$ & $159(53.5 ; 47.7,59.3)$ \\
\hline Solo & $25(9.2 ; 6.2,13.5)$ & $159(53.5 ; 47.7,59.3)$ \\
\hline Hospital & $155(57.2 ; 51.1,63.1)$ & $\mathrm{n} / \mathrm{a}$ \\
\hline Community practice & $132(48.7 ;$;2.6, 54.8) & $\mathrm{n} / \mathrm{a}$ \\
\hline Rehabilitation centre & $9(3.3 ; 1.6,6.4)$ & $\mathrm{n} / \mathrm{a}$ \\
\hline Other & $13(4.8 ; 2.7,8.3)$ & $11(3.7 ; 2.0,6.7)$ \\
\hline
\end{tabular}

n/a not applicable

a Percentages reflect missing data ( 2 or 3 respondents)

${ }^{\mathrm{b}}$ Respondents could check more than one answer

\section{Discussion}

\section{Implication of the findings}

The main aim of this study was to describe the current situation in Quebec respecting interprofessional collaboration between physicians and non-physician osteopaths working with pediatric patients. We found that some collaboration already exists, including referrals and professional relationships between these practitioners, but other factors might improve this collaboration. Having a professional relationship or having personally used osteopathic services were the factors most strongly associated with osteopathic referrals. It is known that consulting a CAM practitioner or having used CAM personally influences CAM referrals for the pediatric population [22, 23]. Indeed, as noted by Mior and collaborators (2010) in the early stages of implementing collaborative care between conventional and CAM practitioners, informal social meetings or events could foster the personal relationships that help to develop mutual respect and trust and break down barriers to communication.

The majority of the survey respondents acknowledged the importance of communication, including exchanging information about common patients. The preferred communication methods were verbal via the patients or

Table 2 Physicians' general knowledge about osteopathic practice parameters and belief in the active role of osteopathy for specific pediatric conditions $(n=274)$

\begin{tabular}{|c|c|}
\hline Currently in Quebec, osteopaths. & Frequency of correct answers (\%) ${ }^{a}$ \\
\hline Do not have a protected title & $122(46.2)$ \\
\hline Have more hours of training than a college degree & $202(76.5)$ \\
\hline Have more hours of training than a bachelor's degree & $147(55.7)$ \\
\hline Have training equivalent to a professional master's degree & $90(34.1)$ \\
\hline Should have WHO osteopathic educational standards & $243(92.0)$ \\
\hline Do not evaluate and mobilize only vertebrae & $267(99.6)$ \\
\hline Are not always physical therapists & $264(98.1)$ \\
\hline Evaluate and mobilize all body tissues & $255(95.1)$ \\
\hline Have extensive knowledge of anatomy, physiology and pathology & $215(81.1)$ \\
\hline Work only with their hands & $135(50.9)$ \\
\hline Do you agree that osteopathic intervention ... & Frequency of positive answers (\%) $)^{a}$ \\
\hline Is appropriate for musculoskeletal pain & $241(91.3)$ \\
\hline Is appropriate for torticollis or positional plagiocephaly & $235(88.0)$ \\
\hline Is not appropriate to evaluate recent, acute, or disabling abdominal pain & $225(85.9)$ \\
\hline Is not appropriate to evaluate severe regurgitation with weight loss & $221(83.7)$ \\
\hline Is not appropriate to relieve pain caused by otitis & $206(78.6)$ \\
\hline Does not speed up the fracture healing process & $183(69.6)$ \\
\hline Is appropriate for colic & $138(52.1)$ \\
\hline Is appropriate for functional disorders (headache, foot alignment, etc.) & $137(51.9)$ \\
\hline Is appropriate for general preventive healthcare & $122(46.4)$ \\
\hline Is appropriate for postnatal preventive healthcare & $114(43.0)$ \\
\hline
\end{tabular}


Table 3 Communication aspects including relationship, referrals and communication methods

\begin{tabular}{|c|c|c|}
\hline \multirow[t]{2}{*}{ Relationship and referrals } & Physicians ( $n=269$ ) & Osteopaths $(n=297)$ \\
\hline & Frequency (\%) & Frequency (\%) \\
\hline Professional relationship (yes) & $96(35.6)$ & $122(41.1)$ \\
\hline Referrals & Typical month & Last 6 months \\
\hline 0 & $104(39.1)$ & $107(36.0)$ \\
\hline 1 & $55(20.7)$ & $45(15.2)$ \\
\hline $2-3$ & $42(15.8)$ & $79(26.6)$ \\
\hline $4-5$ & $13(4.9)$ & $33(11.1)$ \\
\hline More than 5 & $10(3.8)$ & $33(11.1)$ \\
\hline Never under any circumstances & $42(15.8)$ & $\mathrm{n} / \mathrm{a}$ \\
\hline New pediatric patients in osteopathic clinics referred by physicians over a two week period & $\mathrm{n} / \mathrm{a}$ & 269/1293 (20.8) \\
\hline Written referral & $96(35.7)$ & $96(32.3)$ \\
\hline \multirow[t]{2}{*}{ Preferred primary communication method } & Physicians ( $n=107)$ & Osteopaths $(n=126)$ \\
\hline & Frequency (\%) & Frequency (\%) \\
\hline Letter & $38(35.5)$ & $57(45.2)$ \\
\hline Verbal to patient & $39(36.4)$ & $48(38.1)$ \\
\hline Phone & $19(17.8)$ & $8(6.3)$ \\
\hline Email & $5(4.7)$ & $7(5.6)$ \\
\hline In person & $3(2.8)$ & $4(3.2)$ \\
\hline Fax & $3(2.8)$ & $2(1.6)$ \\
\hline \multirow[t]{2}{*}{ Importance of having the other professional among collaborators } & Physicians ( $n=259$ ) & Osteopaths $(n=291)$ \\
\hline & Frequency (\%) & Frequency (\%) \\
\hline Not important & $38(14.7)$ & $8(2.8)$ \\
\hline Slightly important & $77(29.7)$ & $39(13.4)$ \\
\hline Quite important & $113(43.6)$ & $163(56.0)$ \\
\hline Very important & $31(12.0)$ & $81(27.8)$ \\
\hline
\end{tabular}

Sample sizes varied due to non-responses

in writing for practitioners. In a previous study, physicians who recommended that parents of young patients consult with a CAM practitioner reported that sustained two-way communication with CAM practitioners was rare [24]. In the present study, one third of respondents provided parents with a written referral, regardless of profession. In their cross-sectional study on communication regarding pediatric patients, Ben-Arye and collaborators (2007) found that, in addition to communicating clinical information and increasing the willingness to

Table 4 Factors associated with osteopathic referrals by physicians

\begin{tabular}{lll}
\hline & OR $(95 \% \mathrm{Cl})$ & $P$ value \\
\hline Gender (female) & $1.97(0.96,4.02)$ & 0.064 \\
Direct source of information & $1.93(0.98,3.81)$ & 0.058 \\
Belief in active role for pediatric conditions & $1.22(1.01,1.47)$ & 0.042 \\
Community practice & $1.89(1.03,3.47)$ & 0.040 \\
Personal consultation & $2.58(1.35,4.93)$ & 0.004 \\
Professional relationship & $4.10(2.12,7.95)$ & $<0.001$ \\
\hline
\end{tabular}

Stepwise backward logistic regression respond to the initial referral, the exchange of referral letters positively impacted the development of collaboration between physicians and CAM practitioners [25]. Letters about common patients should include conventional/CAM diagnoses using jargon-free terminology, possible conventional/CAM treatment interactions, and treatment plan and goals [26]. Since disclosure and overall discussion about CAM use during physician/patient encounters is reportedly limited $[5,27]$, especially for the pediatric population, verbal exchanges via the patient may not guarantee efficient communication between practitioners compared to exchanging letters.

Communication is also an important catalyst for other determinants of collaboration, such as sharing and developing mutual trust and respect [14]. Mutual respect implies knowledge and recognition of the complementarity of other professionals' contributions [12]. Pediatricians who have a high level of knowledge about CAM are more likely to recommend CAM and discuss CAM with parents [23]. In this study, half the physicians asked 
an osteopath directly for information while about $20 \%$ asked other professionals such as colleagues about the role of osteopathy for pediatric patients. Having such direct sources of information and believing osteopathy to be appropriate for certain pediatric conditions are associated with physicians' greater knowledge of general osteopathic practice parameters. More knowledge about practice parameters may lead to safer, appropriate twoway referrals. However, very few physicians said they had access to continuing education sessions about osteopathy, suggesting that formal education and information transmission concerning osteopathy are rare and could be improved.

Less than half the physicians knew that non-physician osteopaths are not yet regulated in Quebec, suggesting some confusion about the current status of osteopathic practice. However, the majority of respondents, both physicians and osteopaths, expected to be positively influenced by professional regulation and osteopathic university-based education. IPC between conventional and CAM practitioners is known to be affected by systemic determinants such as regulation [16]. For example, practice conditions governed by Colleges of Physicians and Surgeons were found to be a significant barrier to IPC $[15,28]$ and, even when referral to unregulated CAM is allowed, physicians must consider patients' needs in light of medical, legal and ethical issues [29]. A positive view of the upcoming regulation and the creation of osteopathic university-based programs in Quebec might improve interactions between practitioners and increase interprofessional education for future practitioners. More interactions during the training phase might in turn diminish current power disparities observed in practice [30].

\section{Study limitations}

This study has some limitations. First, the low response rate, especially for physicians, may limit the generalizability of the results. Although the response rate is typical for this type of survey [3], lack of time, low perceived relevance of the study topic or receiving more surveys a week might explain the physicians' low response rate [31] compared to the osteopaths. Nearly half the physicians had personally used osteopathic services, which may suggest that those respondents already had a positive attitude toward osteopathy. Since the respondents appeared to be open to and in favour of collaboration, the results likely underestimate the challenges facing collaboration between physicians and osteopaths. To deepen our understanding of IPC between these practitioners, some of the results of this survey are being further explored with qualitative data from purposeful sampling of physicians and osteopaths (phase 2 of the study).

\section{Conclusions}

This study examined the current IPC situation between physicians and non-physician osteopaths working with pediatric patients. Findings suggest that some collaboration already exists, including mutual referrals, but optimizing this collaboration still poses some challenges. Given the pending regulation of the osteopathic profession in Quebec and the need to promote the development of a healthcare delivery model that fosters safe patient-centred care, efforts must be made to reinforce communication skills and opportunities, provide physicians with easily accessible information about osteopathy, and ensure that regulatory bodies establish and maintain relationships after regulation.

\section{Abbreviations}

CAM: Complementary and alternative medicine; IPC: Interprofessional collaboration

\section{Acknowledgments}

Financial support for CM and IG (Junior 1 Researcher) from the Fonds de la Recherche du Québec en Santé (FRQ-S) is gratefully acknowledged.

\section{Funding}

This study was supported in part by the Canadian Interdisciplinary Network for Complementary and Alternative Medicine Research (INCAM). INCAM has no role in the design of the study, the collection, the analysis, and the interpretation of the data or in the writing of the manuscript.

\section{Availability of data and materials}

The datasets used and/or analysed during the current study are available from the corresponding author on reasonable request.

\section{Authors' contributions}

CM, IG and JD designed the survey, analyzed and interpreted the data, drafted the manuscript, revised the manuscript for important intellectual content and approved the final version submitted for publication. CM collected the data.

Ethics approval and consent to participate

The study was approved by the Centre hospitalier universitaire de Sherbrooke ethics committee for health research on humans (\#14-115). Completing and returning the questionnaire anonymously indicate informed consent from participants.

Consent for publication

Not applicable.

\section{Competing interests}

The authors declare that they have no competing interests.

\section{Publisher's Note}

Springer Nature remains neutral with regard to jurisdictional claims in published maps and institutional affiliations.

\section{Author details}

'Department of Family Medicine and Emergency Medicine and School of Rehabilitation, Faculty of Medicine and Health Sciences, Université de Sherbrooke, Sherbrooke, Quebec, Canada. ${ }^{2}$ School of Rehabilitation, Faculty of Medicine and Health Sciences, Université de Sherbrooke, Sherbrooke, Quebec, Canada. 
Received: 22 May 2017 Accepted: 9 November 2017

Published online: 14 November 2017

\section{References}

1. Esmail N. Complementary and alternative medicine in Canada: trends in use and public attitudes, 1997-2006. Vancouver: The Fraser Institute; 2007.

2. Morin C, Aubin A. Primary reasons for osteopathic consultation: a prospective survey in Quebec. PLoS One. 2014;9(9):e106259.

3. Gaboury I, Johnson N, Robin C, Luc M, O'Connor D, Patenaude J, et al. Les médecins se considèrent-ils en mesure de répondre aux exigences du Collège des médecins du Québec? Can Fam Physician. 2016;62(12):e767-71.

4. World Health Organization (WHO). Benchmarks for training in traditional/ complementary and alternative medicine: benchmarks for training in osteopathy. Geneva: WHO Press; 2010.

5. Jean D, Cyr C. Use of complementary and alternative medicine in a general pediatric clinic. Pediatrics. 2007;120(1):e138-41.

6. Amiel-Tison C, Soyez-Papiernik E. Cranial osteopathy as a complementary treatment of postural plagiocephaly. Arch Pédiatr. 2008;15(Suppl 1):S24-30.

7. Gieteling MJ, Lisman-van Leeuwen Y, van der Wouden JC, Schellevis FG, Berger MY. Childhood nonspecific abdominal pain in family practice: incidence, associated factors, and management. Ann Fam Med. 2011;9(4):337-43.

8. King S, Chambers CT, Huguet A, MacNevin RC, McGrath PJ, Parker L, et al. The epidemiology of chronic pain in children and adolescents revisited: a systematic review. Pain. 2011;152(12):2729-38.

9. Williams N, Wilkinson C, Stott N, Menkes DB. Functional illness in primary care: dysfunction versus disease. BMC Fam Pract. 2008;9:30. https://doi.org/ 10.1186/1471-2296-9-30

10. Kluba S, Lypke J, Kraut W, Krimmel M, Haas-Lude K, Reinert S. Preclinical pathways to treatment in infants with positional cranial deformity. Int J Oral Maxillofac Surg. 2014;43(10):1171-5.

11. D'Amour D, Ferrada-Videla M, San Martin Rodriguez L, Beaulieu MD. The conceptual basis for interprofessional collaboration: core concepts and theoretical frameworks. J Interprof Care. 2005;19(Suppl 1):116-31.

12. San Martin-Rodriguez L, Beaulieu MD, D'Amour D, Ferrada-Videla M. The determinants of successful collaboration: a review of theoretical and empirical studies. J Interprof Care. 2005;19(Suppl 1):132-47.

13. Keshet $Y$, Ben-Arye E, Schiff E. The use of boundary objects to enhance interprofessional collaboration: integrating complementary medicine in a hospital setting. Sociol Health IIIn. 2013;35(5):666-81.

14. Mior S, Barnsley J, Boon H, Ashbury FD, Haig R. Designing a framework for the delivery of collaborative musculoskeletal care involving chiropractors and physicians in community-based primary care. J Interprof Care. 2010; 24(6):678-89.

15. Chung VC, Ma PH, Hong LC, Griffiths SM. Organizational determinants of interprofessional collaboration in integrative health care: systematic review of qualitative studies. PLoS One. 2012;7(11):e50022.

16. Hollenberg D, Bourgeault IL. Linking integrative medicine with interprofessional education and care initiatives: challenges and opportunities for interprofessional collaboration. J Interprof Care. 2011;25(3):182-8.

17. Office des professions du Québec. Encadrement de la pratique de l'ostéopathie 2014 [Available from: http://www.opq.gouv.qc.ca/fileadmin/ documents/Actualites/2014/2014 12 17 encadrement osteopathie_02.pdf.

18. Campanelli P. Chapter 10: testing survey questions. In: Leeuw ED, Hox JJ, Dillman DA, editors. International handbook of survey methodology. New York: Lawrence Erlbaum Associates; 2008. p. 176-200. p. 177.

19. Wotruba $\mathrm{S}$. The level of knowledge about osteopathy among medical doctors in private practice in the rural and small-town Weinviertel region. Krems: Danube University; 2010.

20. Hough N, Nicholls B, Kiatos J. A study of physiotherapists' and chiropractors' knowledge and opinion of osteopaths. Melbourne: Victoria University; 2003.

21. Fountain-Polley S, Kawai G, Goldstein A, Ninan T. Knowledge and exposure to complementary and alternative medicine in paediatric doctors: a questionnaire survey. BMC Complement Altern Med. 2007;7:38.

22. Jong MC, van Vliet M, Huttenhuis $S$, van der Veer D, van den Heijkant S. Attitudes toward integrative paediatrics: a national survey among youth health are physicians in The Netherlands. BMC Complement Altern Med 2012;12:4

23. Vlieger AM, van Vliet $M$, Jong MC. Attitudes toward complementary and alternative medicine: a national survey among paediatricians in the Netherlands. Eur J Pediatr. 2011;170(5):619-24.
24. Kundu A, Tassone RF, Jimenez N, Seidel K, Valentine JK, Pagel PS. Attitudes, patterns of recommendation, and communication of pediatric providers about complementary and alternative medicine in a large metropolitan children's hospital. Clin Pediatr. 2011;50(2):153-8.

25. Ben-Arye E, Scharf M, Frenkel M. How should complementary practitioners and physicians communicate? A cross-sectional study from Israel. J Am Board Fam Med. 2007;20(6):565-71.

26. Schiff E, Frenkel M, Shilo M, Levy M, Schachter L, Freifeld $Y$, et al. Bridging the physician and CAM practitioner communication gap: suggested framework for communication between physicians and CAM practitioners based on a cross professional survey from Israel. Patient Educ Couns. 2011; 85(2):188-93.

27. Adams J, Chi-Wai L, Sibbritt D, Broom A, Wardle J, Homer C. Attitudes and referral practices of maternity care professionals with regard to complementary and alternative medicine: an integrative review. J Adv Nurs. 2011;67(3):472-83.

28. Gaboury I, Bujold M, Boon H, Moher D. Interprofessional collaboration within Canadian integrative healthcare clinics: key components. Soc Sci Med. 2009;69(5):707-15.

29. Gilmour J, Harrison C, Asadi L, Cohen MH, Vohra S. Referrals and shared or collaborative care: managing relationships with complementary and alternative medicine practitioners. Pediatrics. 2011;128(Suppl 4):S181-6.

30. Hall P. Interprofessional teamwork: professional cultures as barriers. J Interprof Care. 2005:19(Suppl 1):188-96.

31. Pit $\mathrm{S}$, Vo T, Pyakuel $\mathrm{S}$. The effectiveness of recruitment strategies on general practitioner's survey response rates - a systematic review. BMC Med Res Methodol. 2014;14:76.

\section{Submit your next manuscript to BioMed Central and we will help you at every step:}

- We accept pre-submission inquiries

- Our selector tool helps you to find the most relevant journal

- We provide round the clock customer support

- Convenient online submission

- Thorough peer review

- Inclusion in PubMed and all major indexing services

- Maximum visibility for your research

Submit your manuscript at www.biomedcentral.com/submit
C) Biomed Central 